\title{
Lead Poisoning Surveillance: A Collaborative Effort between Epidemiology and WIC
}

\author{
Kaylee Hervey ${ }^{\star 1}$, Christine Steward ${ }^{1}$, Dante Corimanya1, Sandra Reichenberger ${ }^{2}$, \\ Whitney Crager $^{1}$ and Adrienne Byrne-Lutz ${ }^{1}$
}

${ }^{1}$ Epidemiology, Sedgwick County Health Department, Wichita, KS, USA; ${ }^{2}$ Children and Family Health, Sedgwick County Health

Department, Wichita, KS, USA

\section{Introduction}

There is no safe level of lead in the body, and elevated lead in children can lead to decreased Intelligence Quotients (IQ) and behavioral problems. The American Academy of Pediatrics recommends lead testing of children with a positive risk assessment. Children who live in low socioeconomic areas may be at higher risk for lead exposure. As recent events have shown, having an elevated lead poisoning surveillance system can be critical to ensure that there is not a community-wide lead exposure. To reach the children that may not have been screened by a primary care physician, on March 1, 2016 the Sedgwick County Health Department Women, Infants, and Children (WIC) program began offering lead screenings to all children in the WIC program and their mothers. Per Centers for Disease Control and Prevention (CDC) guidelines, the Sedgwick County Health Department Epidemiology program (Epi) investigates anyone who has an elevated blood lead test $(5 \mu \mathrm{g} / \mathrm{dL}$ or greater). There are two types of lead tests - screening (capillary finger stick) and confirmatory (venous blood draw).

\section{Methods}

Sedgwick County WIC clients are offered screening lead testing at their WIC appointments. Education to reduce lead exposure is provided at the time the test is performed. The filter papers used in this testing are sent to the Kansas Health and Environmental Laboratories (KHEL) for analysis, and the results are reported to Epi. Epi reports the lead testing results to WIC, who track the results in their patient charts. Epi receives KHEL results of $<5 \mu \mathrm{g} / \mathrm{dL}$ via fax and results of $>=5 \mu \mathrm{g} / \mathrm{dL}$ via electronic laboratory reporting in the EpiTrax disease investigation software maintained by the Kansas Department of Health and Environment. Epi notifies any WIC clients with results $>=5 \mu \mathrm{g} / \mathrm{dL}$, while WIC staff notify all other clients about their results. Education is provided to the client a second time by Epi staff and/or a WIC nurse or dietician. For clients with elevated blood lead tests, Epi interviews the case or guardian using an enhanced blood lead exposure questionnaire which asks about potential lead exposures, both in the home and at other locations (work, hobbies, etc.). If only a screening test was performed, Epi recommends confirmatory testing. WIC lead testing program measures, including types of exposures identified, are monitored over time using data obtained from EpiTrax.

\section{Results}

Between March 1 and July 21, of the 2,150 WIC clients offered lead testing, $89 \%$ self-reported never having received a lead test previously. Of the 1,427 clients with WIC lead screening results, seven cases of elevated blood lead were identified. Of the seven, five did not have a previous elevated lead test in EpiTrax. The average screening test result was $8.6 \mu \mathrm{g} / \mathrm{dL}$ (range 6.8 to 13.4). The average age of the cases was 2 years (range 1-4). Of the seven cases, two (29\%) were confirmed as 10.0 and $11.0 \mu \mathrm{g} / \mathrm{dL}$ through venous testing at their primary care provider's office. The remaining five cases have not received confirmatory testing. One of the three cases interviewed reported that their babysitter lived in an old home, which could be the source of lead exposure. While interviewing a child's guardian about an elevated 2016 test $(7.9 \mu \mathrm{g} / \mathrm{dL})$, Epi discussed a previous 2015 elevated lead test $(6.0 \mu \mathrm{g} / \mathrm{dL})$ of which the client's guardian was unaware.

\section{Conclusions}

The ease of access to lead testing in the Sedgwick County WIC program and the joint effort between WIC and Epi to implement an enhanced lead poisoning surveillance system identified six children with elevated lead levels whose guardians did not know they had elevated lead levels. This new surveillance program educates WIC parents about lead, determines the lead levels in children for guardian knowledge (low level) and further follow-up (elevated level), and identifies lead exposures of WIC children with elevated lead tests.

\section{Keywords}

lead; surveillance system; WIC

\section{*Kaylee Hervey}

E-mail: Kaylee.Hervey@sedgwick.gov 